\title{
Integrative Analysis of DNA Methylation and Gene Expression Identify a Three- Gene Signature for Predicting Prognosis in Lower-Grade Gliomas
}

\author{
Wen-Jing Zeng ${ }^{a, b}$ Yong-Long Yang ${ }^{c}$ Zheng-Zheng Liu ${ }^{d}$ Zhi-Peng Wen ${ }^{a, b}$ \\ Yan-Hong Chen ${ }^{a, b}$ Xiao-Lei Hua,b Quan Cheng ${ }^{e}$ Jian Xiao ${ }^{f}$ Jie Zhao \\ Xiao-Ping Chen ${ }^{a, b}$ \\ aDepartment of Clinical Pharmacology, Xiangya Hospital, Central South University, Changsha, \\ Hunan, 'Institute of Clinical Pharmacology, Central South University, Hunan Key Laboratory of \\ Pharmacogenetics, Changsha, Hunan, 'Haikou People's Hospital and Affiliated Haikou Hospital of \\ Xiangya Medical School, Central South University, Haikou, Hainan, ${ }^{\mathrm{d} D e p a r t m e n t ~ o f ~ O n c o l o g y, ~ X i a n g y a ~}$ \\ Hospital, Central South University, Changsha, Hunan, eNeurosurgery, Xiangya Hospital, Central South \\ University, Changsha, Hunan, 'Department of Pharmacy, Xiangya Hospital, Central South University, \\ Changsha, Hunan, P. R. China
}

\section{Key Words}

Lower-grade glioma $\cdot$ Promoter methylation $•$ Prognosis $\bullet$ Signature

\begin{abstract}
Background/Aims: In the current study, we performed an integrated analysis of genomewide methylation and gene expression data to find novel prognostic genes for lower-grade gliomas (LGGs). Methods: First, TCGA methylation data were used to identify prognostic genes associated with promoter methylation. Second, candidate genes that were stably regulated by promoter methylation were explored. Third, Cox proportional hazards regression analysis was used to generate a prognostic signature, and the signature genes were used to construct a survival risk score system. Results: Three genes (EMP3, GSX2 and EMILIN3) were selected as signature genes. These three signature genes were used to construct a survival risk score system. The high-risk group exhibited significantly worse overall survival (OS) and relapsefree survival (RFS) as compared to the low-risk group in the TCGA dataset. The association of the three-gene prognostic signature with patient' survival was then validated using the CGGA dataset. Moreover, Kaplan-Meier plots showed that the three-gene prognostic signature risk remarkably stratified grade II and grade III patients in terms of both OS and RFS in the TCGA cohort. There was also a significant difference between the low- and high-risk groups in IDH wild-type glioma patients, indicating that the three-gene signature may be able to help in
\end{abstract}


predicting prognosis for patients with IDH wild-type gliomas. Conclusion: We identified and validated a three-gene (EMP3, GSX2 and EMILIN3) prognostic signature in LGGs by integrating multidimensional genomic data from the TCGA and CGGA datasets, which may help in fine-tuning the current histology-based tumors classification system and providing better stratification for future clinical trials.

(C) 2018 The Author(s)

Published by S. Karger AG, Basel

\section{Introduction}

Gliomas are the most common primary malignancies in the central nervous system and show great heterogeneity in terms of their histopathology and clinical outcomes. According to the 2016 World Health Organization (WHO) classification system, gliomas include astrocytoma, oligoastrocytoma, oligodendroglioma and glioblastoma (GBM), and ranged in grades I to IV $[1,2]$. Lower-grade gliomas (LGGs), which include WHO grades II and III astrocytoma, anaplastic astrocytoma, oligodendroglioma and anaplastic oligodendroglioma, exhibit an infiltrative nature and an intrinsic tendency to recur or progress to glioblastoma, a WHO grade IV glioma [1,3]. Because of their highly invasive nature, complete neurosurgical resection is impossible for LGGs. The presence of residual tumor usually results in recurrence and malignant progression, albeit at highly variable intervals [4]. The survival of LGGs ranges widely, from 1 to 15 years, and some LGGs patients show impressive therapeutic sensitivity [5]. Though molecular diagnosis has been adopted in the classification of LGGs to create a more objective and precise tumor classification system [6, 7], the known molecular markers can only partly explain LGG prognosis at present. Thus, continued efforts to improve prediction accuracy and facilitate therapeutic strategies for LGGs are warranted.

DNA methylation is a vital form of epigenetic modification that is involved in the pathogenesis of cancer [8]. Promoter methylation of the gene encoding 06-methylguanineDNA methyltransferase (MGMT) is closely related with its activity and can effectively predict gliomas' responsiveness to alkylating agents $[9,10]$. Increased methylation in 5' upstream regulatory sites is negatively correlated with the expression of some tumor-suppression genes [11], which suggests that alterations in DNA methylation may have potential uses in the functional characterization and diagnosis of gliomas.

Transcriptomic data are typically used to explore the underlying characteristics of cancer and design new drug targets. Verhaak et al. classified GBM into Proneural, Neural, Classical, and Mesenchymal subtypes by using gene expression data of GBM [12]. Weller et al. have also identified eight transcriptionally different groups (five IDH1/2 mutant and three $I D H 1 / 2$ wild types) of glioma by analyzing transcriptome-wide data derived from primary tumor samples [13]. Recent studies have confirmed that IDH mutation can impair histone demethylation [14] and predict better survival for glioma patients $[15,16]$. However, current molecular classification cannot ensure the precise diagnosis and personalized medicine for LGG patients.

In this study, LGG DNA methylation data from The Cancer Genome Atlas (TCGA) and transcriptomic data from TCGA and the Chinese Glioma Genome Atlas (CGGA) were used to identify novel prognostic genes that are potentially regulated by promoter methylation. The relationships between DNA promoter methylation and gene expression as well as disease survival were analyzed for LGG patients. We believe that the findings will help to further improve molecular diagnosis and individualized therapy for LGGs.

\section{Materials and Methods}

Lower-grade glioma datasets

TCGA LGG datasets, including DNA methylation and gene expression data obtained from the same patient' population, were downloaded from the University of California, Santa Cruz, cancer browser: https://genome-cancer.ucsc.edu/ (Version: 2015-02-24). The DNA methylation data were generated by 
the Illumina Infinium Human Methylation 450 platform. The gene promoter methylation status was obtained by calculating the average of all CpG sites in a given promoter region. According to the Illumina Infinium Human Methylation450 platform annotation file, the promoter regions included TSS1500, TSS200, and the 5' untranslated region (5'UTR) [17]. Gene expression data from the TCGA LGG dataset were obtained from the Illumina HiSeq 2000 RNA Sequencing platform. In total, 473 samples (225 grade II and 248 grade III LGGs) with clinical information were eligible for the prognosis analysis and the correlation analysis between DNA methylation and gene expression levels. The CGGA microarray dataset, which was generated by Agilent Whole Human Genome Array (http://cgga.org $\mathrm{cn} /$ ), was also downloaded for use as a validation dataset. From this dataset, 131 samples (97 grade II and 34 grade III) were included, and the clinical data were also downloaded for prognostic analysis. The clinical characteristics of LGG patients in the TCGA and CGGA datasets were shown in Table 1.

\section{Prognosis and correlation analysis}

Overall survival (OS) and relapse-free survival (RFS) were used to indicate prognosis in our analysis. OS is defined as the time interval between resection and the date of death or the last follow-up. RFS is the period from resection to the first radiological evidence of tumor recurrence. To evaluate the prognostic value of DNA promoter methylation in TCGA LGG patients, promoter methylation status was stratified using four different cut-off values, which included the mean, the median (=the second quartile), quartile (the first quartile versus the third quartile) and the beta value $=0.5$. The beta value was used to estimate the methylation level of the probes. Methylation was considered to have prognosis significance when an adjusted $P<0.05$ occurred for all four cut-off values. The correlation between promoter methylation level and the mRNA expression of the corresponding gene was investigated by using Spearman's correlation analysis [18]. A Spearman $|r| \geq 0.6$ with an adjusted $P<0.05$ indicated a strong and significant correlation [19]. Cox proportional hazard regression analysis was performed to analyze the influence of gene expression on disease prognosis. The prognostic genes generated from above TCGA LGG dataset were then validated using the CGGA microarray dataset to further determine the genes' prognostic significance in LGG patients. The analysis flow chart was shown in Fig. 1.
Table 1. Clinical characteristics of the lower-grade glioma datasets. Notes: TCGA: The Cancer Genome Atlas; CGGA: Chinese Glioma Genome Atlas; KPS: karnofsky performance score; IDH: isocitrate dehydrogenase; MGMT: 0-6-methylguanine-DNA methyltransferase; TERT: Telomerase reverse transcriptase; ATRX: Alpha thalassemia/mental retardation syndrome $\mathrm{X}$-linked; $\mathrm{NR}=$ not recorded

\begin{tabular}{|c|c|c|}
\hline & TCGA cohort & CGGA cohort \\
\hline No. of patients & 473 & 131 \\
\hline Age, mean (year) & 43 & 39.9 \\
\hline \multicolumn{3}{|l|}{ Sex, No. (\%) } \\
\hline male & $260(54.9)$ & $72(55.0)$ \\
\hline female & $212(44.8)$ & $59(45.0)$ \\
\hline \multicolumn{3}{|l|}{ WHO Grade, No. (\%) } \\
\hline II grade & $225(47.6)$ & $97(74.0)$ \\
\hline III grade & $248(52.4)$ & $34(26.0)$ \\
\hline \multicolumn{3}{|l|}{ KPS, No. (\%) } \\
\hline $\mathrm{KPS}>70$ & $266(56.2)$ & $113(86.2)$ \\
\hline $\mathrm{KPS} \leq 70$ & $18(3.8)$ & $18(13.8)$ \\
\hline unknown & $189(40.0)$ & $0(0)$ \\
\hline \multicolumn{3}{|l|}{ IDH status, No. (\%) } \\
\hline IDH mutant & $383(81.0)$ & $84(64.1)$ \\
\hline IDH wild type & $88(18.6)$ & $45(34.4)$ \\
\hline unknown & $2(0.4)$ & $2(1.5)$ \\
\hline \multicolumn{3}{|l|}{ 1p/19q codeletion, No. (\%) } \\
\hline 1p/19q non-codeletion & $316(66.8)$ & - \\
\hline \multirow{2}{*}{\multicolumn{3}{|c|}{ MGMT promoter methylation, No. (\%) }} \\
\hline & & \\
\hline unmethylated & $81(17.1)$ & - \\
\hline methylated & $392(82.9)$ & - \\
\hline \multicolumn{3}{|l|}{ TERT promoter status, No. (\%) } \\
\hline TERT mutant & $132(27.9)$ & - \\
\hline TERT wild type & $166(35.1)$ & - \\
\hline unknown & $175(37.0)$ & - \\
\hline \multicolumn{3}{|l|}{ ATRX status, No. (\%) } \\
\hline ATRX mutant & $174(36.8)$ & - \\
\hline ATRX wild type & $297(62.8)$ & - \\
\hline unknown & $2(0.4)$ & - \\
\hline \multicolumn{3}{|l|}{ Radiotherapy, No. (\%) } \\
\hline Yes & $274(57.9)$ & NR \\
\hline No & $166(35.1)$ & NR \\
\hline unknown & $33(7.0)$ & NR \\
\hline \multicolumn{3}{|l|}{ Temozolomide (TMZ), No. (\%) } \\
\hline Yes & $74(15.6)$ & NR \\
\hline No & 88 (18.6) & NR \\
\hline unknown & $311(65.8)$ & NR \\
\hline
\end{tabular}

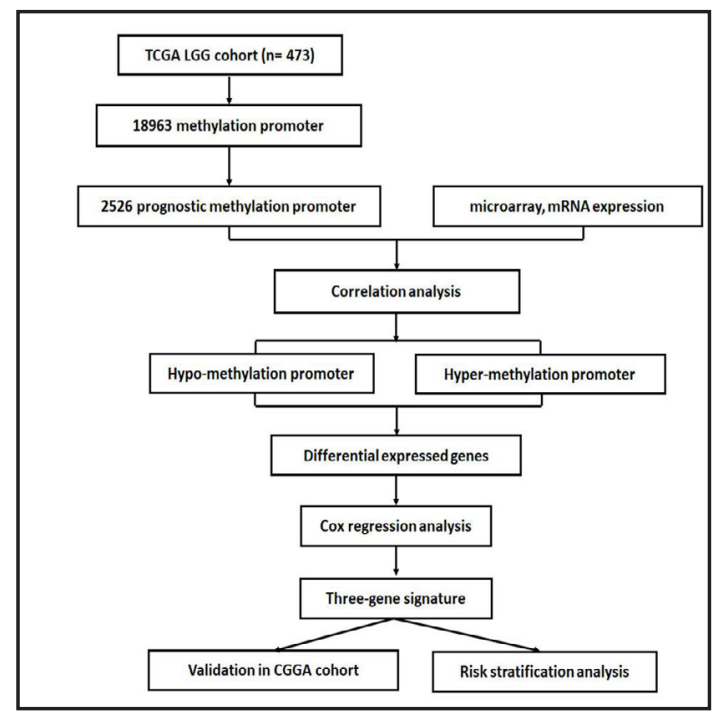

Fig. 1. Flow chart of procedure for building the three-gene signature based on TCGA and CGGA datasets. 


\section{Cellular Physiology Cell Physiol Biochem 2018;47:428-439 \begin{tabular}{ll|l} 
and Biochemistry & Dublished online: May 22, 2018 & $\begin{array}{l}\text { (c) } 2018 \text { The Author(s). Published by S. Karger AG, Basel } \\
\text { www.karger.com/cpb }\end{array}$
\end{tabular}

\section{Statistical analysis}

Statistical analyses were performed with R software (Version 3.3.1), SPSS 13.0 (SPSS Inc., Chicago, IL, USA), and GraphPad Prism 5.0 (Graphpad Inc., San Diego, CA, USA). Comparisons between groups were performed using Student's $t$-tests. Kaplan-Meier survival analysis was performed to assess the survival profiles, and log-rank test was performed to determine the significance of the differences between groups. Univariate Cox proportional hazards regression analysis was carried out to assess the association between gene expression and overall survival. For the multivariable analysis, a Cox proportional hazards model was established for OS and RFS with a limited forward-LR procedure, which was adjusted for potential confounding covariates. Hazard ratio (HRs) and 95\% confidence intervals (CIs) were used to describe the relative risk. Statistical significance was accepted when $P<0.05$.

\section{Results}

Whole-genome analysis of gene promotermethylation's effect on LGGs prognosis based on TCGA dataset

We first extracted data regarding gene promoter $\mathrm{CpG}$ sites from the Illumina Infinium $\mathrm{Hu}$ m a $\mathrm{Me}$ e hyla tion 450 platform. A total of 129, 225 promoter CpG sites in 18, 963 mapping Refseq-annotated genes were selected. The methylation status for each gene promoter in each sample was obtained by calculating the average of all $\mathrm{CpG}$ sites in the same promoter region. A total of 2526 promoter methylation showed significant association with LGG patients' overall survival at four cut-off values (adjusted $P<0.05$, (for all online suppl. material, see www.karger. com/doi/10.1159/000489954) Suppl. Table 1).

Identification of gene
promoter methylation
relevant gene expression
changes in LGGs
correlation between promoter methylation and gene expression changes, both the DNA methylation and the gene expression data for 473 samples from the TCGA dataset were downloaded and Spearman's nonparametric correlation analysis was carried out. We

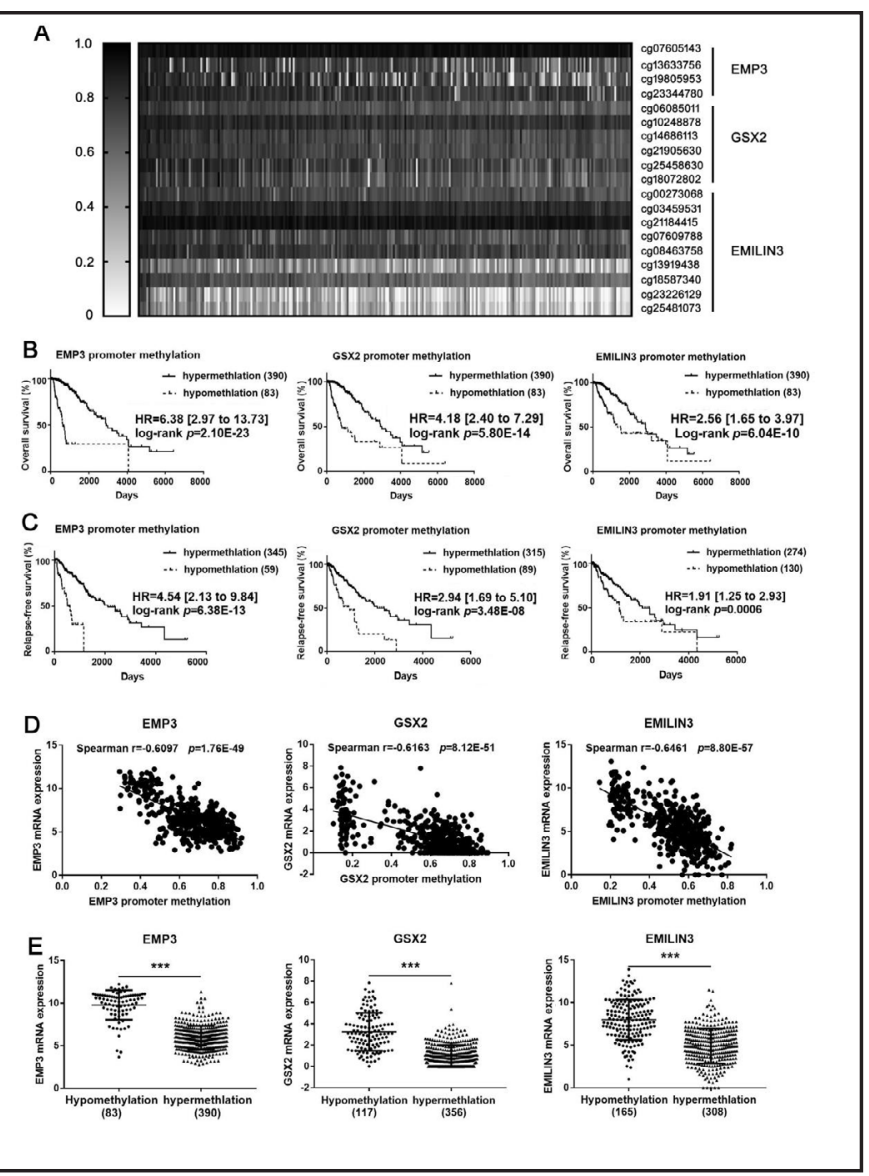

Fig. 2. The association of EMP3, GSX2 and EMILIN3 promoter methylation with its gene expression, as well as patients' survival. (A) Heatmap of Methylation Probes in EMP3, GSX2 and EMILIN3 promoter regions. (B) Kaplan-Meier plot for overall survival (OS) between patients with hyper-methylation and hypo-methylation of EMP3, GSX2 and EMILIN3 promoter in TCGA dataset. (C) KaplanMeier plot for relapse-free survival (RFS) between patients with hyper-methylation and hypo-methylation of EMP3, GSX2 and EMILIN3 promoter in TCGA dataset. (D) The correlation between three genes promoter methylation status and gene expression levels was assessed using Spearman's correlation analysis. (E) The mRNA expression of EMP3, GSX2 and EMILIN3 in hypermethylation and hypo-methylation promoter groups. The results are mean $\pm \mathrm{SD}, * * * \mathrm{P}<0.001$ 
observed that mean promoter methylation levels were strongly negatively correlated with corresponding gene expression for 100 genes (Spearman $\mathrm{r}<-0.6$ and adjusted $P<0.05$, see online suppl. material, Suppl. Table 2). To further investigate whether the promoter methylation of the 100 negatively correlated genes affected stable gene expression, the samples were divided into two groups using a methylation beta value $=0.5$ as the cut-off value. The inclusion criteria were a $>1.5$-fold change in gene expression and an adjusted $P<0.05$ between the hypo- and hyper-methylation groups. We also investigated the association of gene expression with overall survival using univariate Cox proportional hazard regression analysis $(P<0.05)$. Of the 100 genes included, eleven genes (LOC100130776, NCRNA00092, RBP1, TSTD1, TOM1L1, DDIT4L, EMILIN3, PRICKLE3, EMP3, GSX2 and NSUN7) met the above criteria (adjusted $P<0.05$ between the hypo- and hyper-methylation groups; gene expression level associated with $0 S$; see online suppl. material, Suppl. Table 3). The eleven candidate genes were thenused to constructa prognostic signature using a multivariable Cox proportional hazards model. Finally, three genes, EMP3, GSX2 and EMILIN3, were selected as signature genes, and correlations between promoter methylation and genes expression for EMP3, GSX2 and EMILIN3 were shown in Fig. 2.

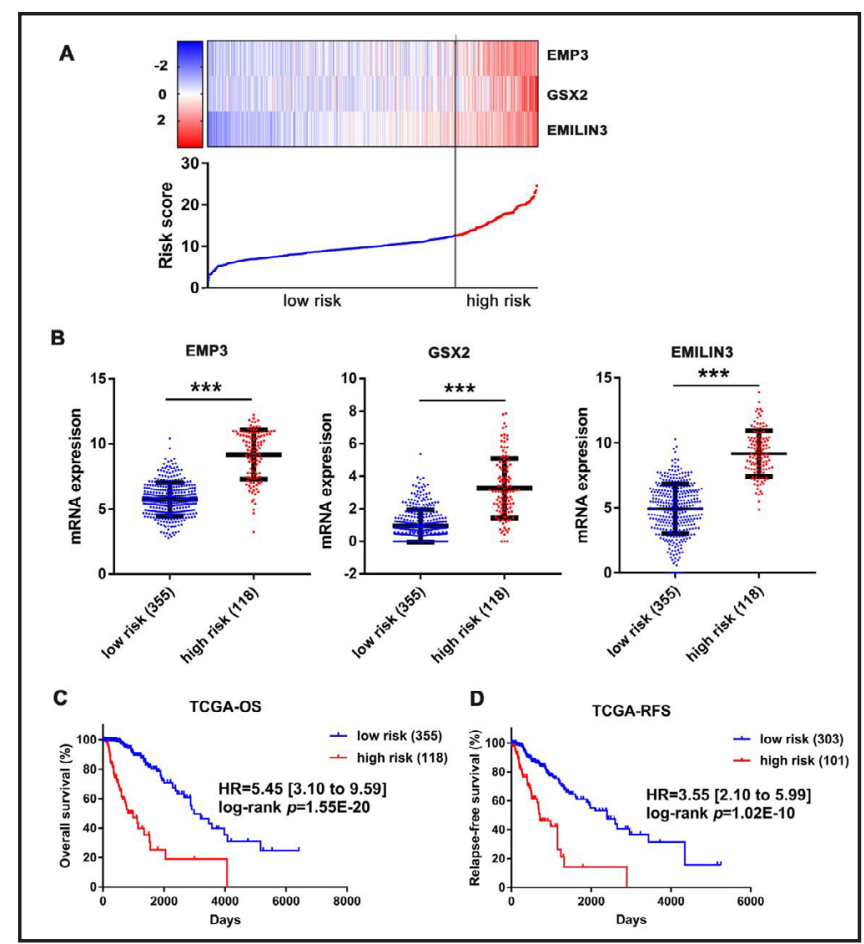

Fig. 3. Identification of the three-gene prognostic signature with TCGA LGGs cohort. (A) The distribution of three-gene expression and risk score in TCGA cohort, the expression of three genes were transformed by z-score, with red indicating higher expression and blue indicating lower expression. The risk scores for all patients in TCGA LGGs cohort are plotted in ascending order and marked as low-risk (blue) or high-risk (red), as divided by the threshold (vertical black line). (B) The EMP3, GSX2 and EMILIN3 mRNA was differentially expressed between high and low-risk groups. The results are mean \pm SD, $* * * \mathrm{P}<0.001$. Kaplan-Meier plot for OS (C) and RFS (D) in TCGA LGGs cohort stratified by three-gene prognostic signature in high and low-risk.

Table 2. Cox proportional hazards models of the three-gene signature risk scores in TCGA LGGs cohort. Notes: HR: hazard ratio; CI: confidence interval; KPS: karnofsky performance score

\begin{tabular}{|c|c|c|c|c|}
\hline \multirow{2}{*}{ Overall survival } & \multicolumn{2}{|c|}{ Univariate } & \multicolumn{2}{|r|}{ Multivariate } \\
\hline & P-value & HR[95\%Cl] & P-value & $\mathrm{HR}[95 \% \mathrm{CI}]$ \\
\hline Age (year): $>40$ vs $\leq 40$ & $3.37 \mathrm{E}-15$ & $1.070[1.052-1.89]$ & $9.38 \mathrm{E}-15$ & $1.058[1.053-1.071]$ \\
\hline Gender: male vs female & 0.4686 & $1.165[0.770-1.763]$ & ns & \\
\hline $\mathrm{KPS}: \leq 70$ vs $>70$ & 0.0113 & $2.129[1.187-3.820]$ & ns & \\
\hline Tumor grade: Grade III vs II & $5.0 \mathrm{E}-06$ & $2.851[1.821-4.465]$ & 0.023 & $1.745[1.080-2.819]$ \\
\hline Risk score: high vs low & $1.19 \mathrm{E}-18$ & $6.374[4.223-9.662]$ & $5.15 \mathrm{E}-13$ & $5.813[3.605-9.372]$ \\
\hline
\end{tabular}

Generation and validation of

three-gene prognostic signature

We further constructed a survival risk score system using the regression coefficient from the multivariable Cox proportional hazards model. The risk score was calculated as follows: risk score $=\left(0.597^{*}\right.$ expression level of EMP3 $+0.825^{*}$ expression level of GSX2 + $0.942 *$ expression level of EMILIN3). Patients were divided into low-risk and high-risk groups according to their risk scores, and the cut-off value was set at $75^{\text {th }}$ percentile [20] (Fig. 3A). As shown in Fig. 3B, the three signature genes were remarkably overexpressed in the high-risk 
Fig. 4. Validation of the three-gene prognostic signature with CGGA LGGs cohort. (A) The distribution of threegene expression and risk score in CGGA LGGs cohort, with red indicating higher expression and light blue indicating lower expression. The risk scores for all patients in CGGA cohort are plotted in ascending order and marked as low-risk (blue) or high-risk (red), as divided by the threshold (vertical black line). (B) The EMP3, GSX2 and EMILIN3 mRNA was differentially expressed between high and low-risk groups. The results are mean $\pm \mathrm{SD}$, $* * * P<0.001$. (C) Kaplan-Meier plot for OS between high and low-risk groups in CGGA LGGs cohort.

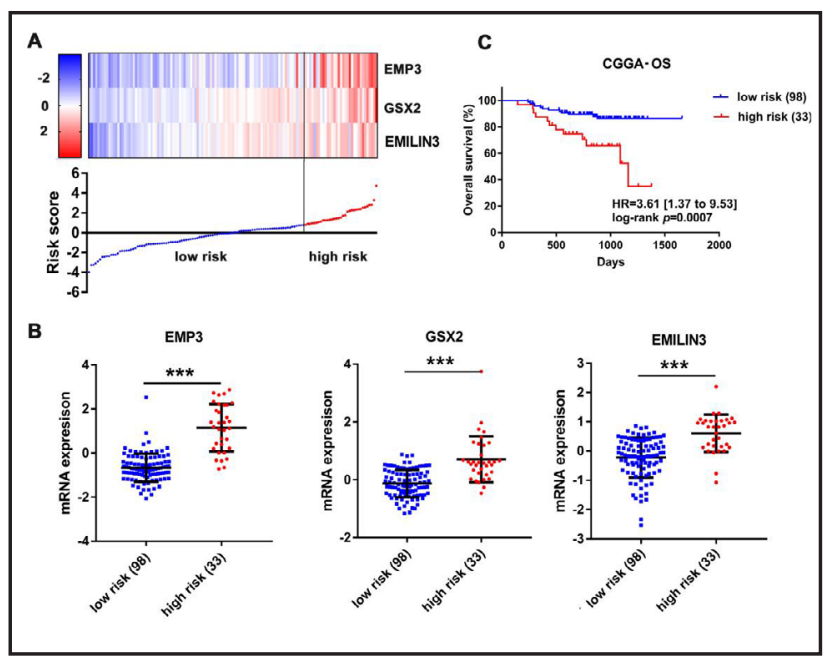

Fig. 5. Three-gene signature performance in grade II and III and IDH1 wild-type subsets in the TCGA LGGs cohort. (A) Comparison of the threegene signature with the molecular subtypes and the cluster from Ceccarelli et al. for 471 LGG samples from the TCGA database. The three-gene signature is indicated in the first row. (B and D) KaplanMeier survival plots for OS and RFS between grade II and grade III patients in the TCGA LGGs cohort. (C) Kaplan-Meier plot for OS between grade II or grade III patients with high-risk and low-risk in TCGA lower-grade glioma patients. (E) Kaplan-Meier plot for RFS between grade II or grade III patients with high-risk and low-risk in TCGA lower-grade glioma patients. (G) KaplanMeier survival plots for
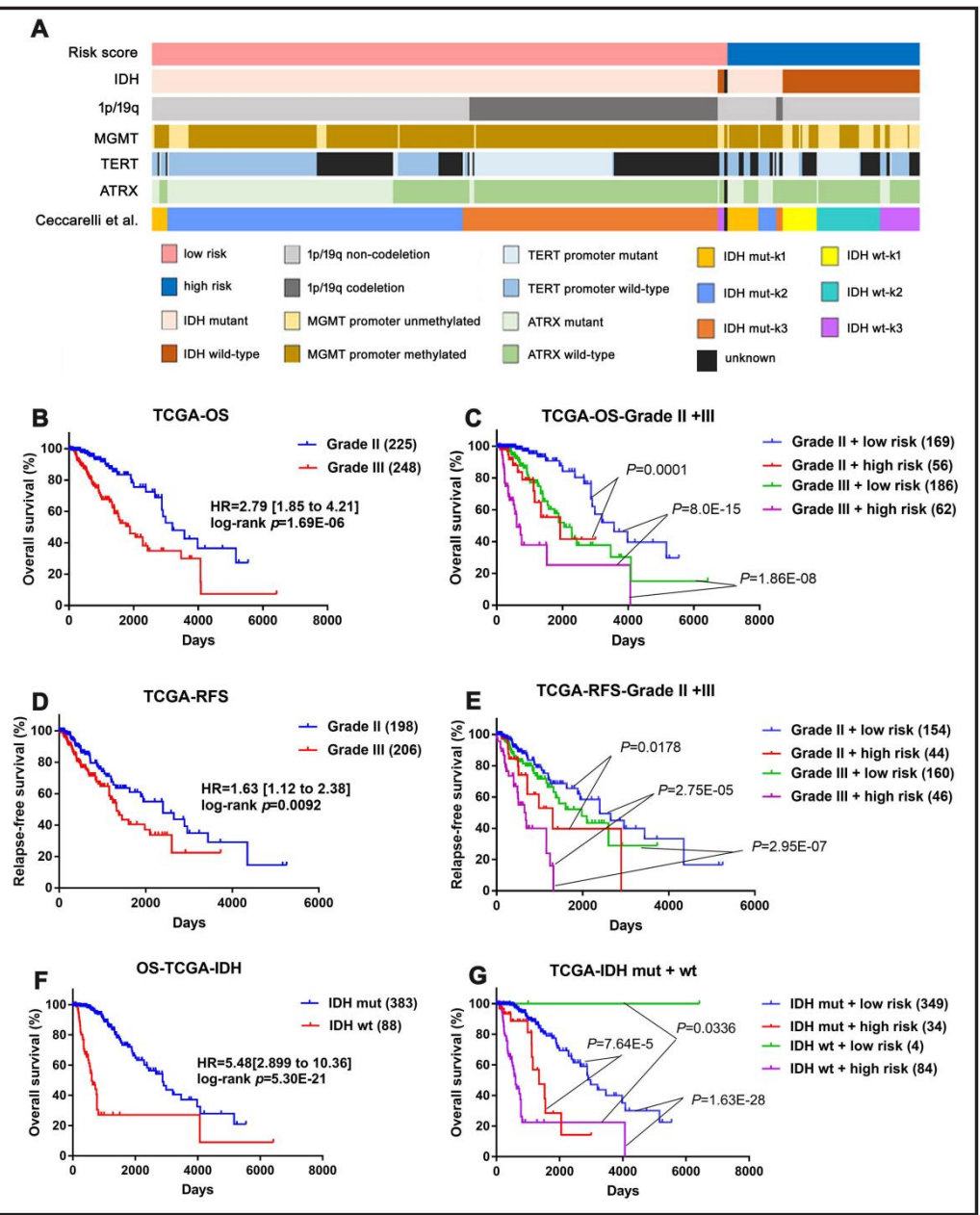
OS between IDH mutant patients and wild type patients in the TCGA LGGs cohort. (H) Kaplan-Meier survival plots for OS between IDH mutant patients and wild-type patients with high-risk and low-risk in the TCGA LGGs cohort. 
group. In addition, the high-risk group exhibited significantly worse OS $\quad(\mathrm{HR}=5.45$, 95\% $\mathrm{CI}=3.10-9.59, P=1.55 \mathrm{E}-20$ ) and RFS (HR=3.55, 95\%CI=2.10-5.99, $P=1.02 \mathrm{E}-10$ ) as compared with the low-risk group after adjusting for age, Karnofsky performance score (KPS) and tumor grade (Fig. 3C and $\mathrm{D}$, Table 2).

The CGGA dataset was used to validate the three-gene prognostic signature obtained from the TCGA LGGs dataset. Based on the same risk score cut-off value as the TCGA LGGs dataset, CGGA LGG patients were grouped into low-risk and high-risk groups. Significant differences in the expression levels of all three genes were observed between the two groups (Fig. 4A and B). Kaplan-

Meier plot indicated that the high-risk group exhibited significantly worse OS as compared with the low-risk group ( $\mathrm{HR}=3.61,95 \% \mathrm{CI}=1.37-9.53, P=0.0007$, Fig. $4 \mathrm{C})$.

\section{Clinical and molecular features of low- and high-risk LGG patients}

Comparison of the three-gene signature with the molecular subtypes and the cluster from Ceccarelli et al. for 473 LGG samples from the TCGA database were shown in Fig. $5 \mathrm{~A}$. To explore the three-gene signature with respect to prognosis among glioma patients within WHO grades II and III, we further investigated the association between risk score and survival in patient data from the TCGA cohort. As shown in Fig. 5B and D, patients with grade III glioma exhibited significantly worse OS (HR=2.79, 95\%CI=1.85-4.21, $P=1.69 \mathrm{E}-06)$ and RFS $(\mathrm{HR}=1.63,95 \% \mathrm{CI}=1.12-2.38, P=0.0092)$ than those with grade II glioma. Moreover, the three-gene prognostic signature risk stratified grade II and grade III patients remarkably well in terms of both OS (grade II + high-risk vs grade II + lowrisk: $\mathrm{HR}=3.92,95 \% \mathrm{CI}=1.28-12.06, P=0.0001$; grade III + high-risk $v s$ grade III + low-risk: $\mathrm{HR}=3.61,95 \% \mathrm{CI}=1.87-6.94, P=1.86 \mathrm{E}-08$, Fig. $5 \mathrm{C}$ ) and RFS (grade II + high-risk $v s$ grade II + low-risk: $\mathrm{HR}=2.15,95 \% \mathrm{CI}=0.94-4.92, P=0.0178$; grade III + high-risk vs grade III + low-risk: $\mathrm{HR}=3.48,95 \% \mathrm{CI}=1.72-7.06, P=2.95 \mathrm{E}-07$, Fig. $5 \mathrm{E}$ ). When both WHO grade and the risk score were considered concomitantly, the grade II patients in the low-risk group showed the best outcomes, while the patients with grade III glioma in the high-risk group showed the worst outcome (Fig. 5C and E).

$I D H$ mutation is a widely acknowledged molecular marker that predicts better prognosis for LGG patients [12,14,21]. IDH mutation status was known for 471 patients in the TCGA LGGs cohort. We observed that $I D H$ mutant patients showed significantly better OS as compared with $I D H$ wild-type patients $(\mathrm{HR}=5.48,95 \% \mathrm{CI}=2.899-10.36, P=5.30 \mathrm{E}-21$, Fig. $5 \mathrm{~F}$ ). To clarify whether the three-gene signature acted independently of the $I D H$ mutation as a prognostic indicator for LGGs, we evaluated the association between risk-score and prognosis in LGG patients stratified by IDH mutation status. As shown in Fig. 5G, a significant difference in OS was observed between the high- and low-risk groups in the $I D H$ wild-type patients (HR=3.545, 95\% $\mathrm{CI}=1.42-35.75, P=0.0336)$, and this association was also observed among $I D H$ mutant patients $(\mathrm{HR}=3.44,95 \% \mathrm{CI}=1.103-11.40)$. When both risk score and 


\section{Cellular Physiology Cell Physiol Biochem 2018;47:428-439 \\ \begin{tabular}{c|c} 
DOI: 10.1159/000489954 & O 2018 The Author(s). Published by S. Karger AG, Basel \\
wwww.karger.com/cpb
\end{tabular} \\ Zeng et al.: Three-Gene Signature for Lower-Grade Gliomas}

IDH mutation status were considered, we observed that IDH wild-type patients with highrisk scores showed the worst prognosis. We further validated the findings using the CGGA dataset (Fig. 6). These data indicated that the three-gene signature may act as a prognostic factor for patients with $I D H$ wild-type gliomas.

\section{Discussion}

Despite recent progress in neurosurgery, radiotherapy and chemotherapy, the survival of LGG patients ranges widely. To improve prediction accuracy and facilitate therapeutic strategies for LGGs, the genetic and epigenetic landscapes of LGGs have been extensively studied $[3,14,16,22,23]$. In the case of LGGs, IDH, ATRX, TP53, TERT and 1p/19q codeletion are well-established genetic markers. In particular, $I D H$ mutation and $1 \mathrm{p} / 19 \mathrm{q}$ deletion were adopted as biomarkers for classifying gliomas in the 2016 WHO classification of central nervous system tumors [1]. DNA methylation, an epigenetic modification via the methylation of cytosin in carbon 5, has been widely reported in human gliomas [24-26]. For example, about $40 \%$ of gliomas present with MGMT promoter methylation, which acts as a responsiveness biomarker for alkylating agents $[9,10]$. However, the role of epigenetic alterations in LGGs and the potential role of DNA methylation as a prognostic biomarker remain largely unclear.

In this study, we first utilized the TCGA methylation data to identify prognostic genes associated with promoter methylation. Next, we screened for genes that were stably regulated by promoter methylation. Then, the Cox proportional hazards regression analysis was carried out to generate a prognostic signature. We observed that this three-gene (EMP3, GSX2 and EMILIN3) signature can be used as a prognostic indicator for LGGs patients from both the TCGA and the CGGA datasets. EMP3 is a member of the PMP22/EMP/MP20 gene family that plays a role in cell proliferation and cell-cell interactions [27]. Previous studies reported that $\mathrm{CpG}$ island hypermethylation in the EMP3 promoter region is frequent in LGGs [28-30]. Moreover, EMP3 promoter hypermethylation is associated with a favorable prognostic significance in OS in patients with oligodendroglial and glioblastoma $[29,31$, 32]. In line with previous studies, we found that promoter methylation in EMP3 correlated negatively with its expression and lower EMP3 expression predicted better prognosis in LGGs patients. Our findings further support an oncogenic role on the part of EMP3 in glioma. Of course, the exact role of EMP3 in the development of glioma requires further investigation.

GSX2 (GS homeobox 2, also known as GSH2) is a brain-specific class II homeobox gene that is involved in brain development and neuronal differentiation. The role of GSX2 in tumor development is contradictory. In pancreatic cancer, GSX2 has been identified as a novel methylation-sensitive tumor suppressor gene and associated with tumor nose metastasis stage [33]. However, studies in acute myeloid leukemia have suggested GSX2 as a putative oncogene [34-36]. The influence of GSX2 promoter methylation on LGGs prognosis remains largely unknown. In this study, we found that hypermethylation of the GSX2 promoter was correlated negatively with its mRNA expression and that GSX2 hypomethylation and higher GSX2 mRNA expression were associated with worse OS and RFS in LGG patients.

EMILIN3 (elastin microfibril interfacer 3), a glycoprotein of the extracellular matrix, belongs to the elastin microfibril interface-located protein (MEILIN)/multimerin family. Previous study using whole genome copy number variation (CNV) analysis revealed that the EMILIN3 gene was significantly increased in copy number in colorectal cancer samples as compared to non-cancerous samples [37]. However, the role of EMILIN3 in gliomas remains unclear. In this study, we found that higher EMILIN3 expression was associated with worse OS and RFS in LGG patients and that promoter methylation in EMLIN3 was negatively correlated with gene expression. According to previous studies, the mechanism via which EMILIN3 affects glioma development may be explained by its interaction with heparin and heparin sulfate proteoglycans (HSPG) on the extracellular matrix [38-40]. Further studies are needed to explore the exact mechanisms of EMILIN3 in the tumor microenvironment 


\section{Cellular Physiology Cell Physiol Biochem 2018;47:428-439

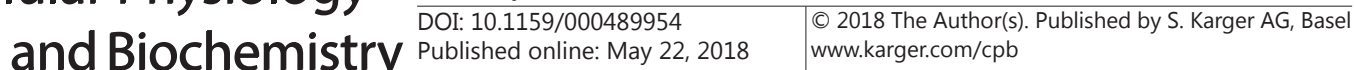 \\ Zeng et al.: Three-Gene Signature for Lower-Grade Gliomas}

and its pro-tumorigenic function in gliomas.

The survival differences between WHO grade II and WHO grade III gliomas were highly significant, and some LGGs patients showed impressive therapeutic sensitivity $[3,5]$. Our results indicated that the three-gene prognostic signature risk score could precisely predict clinical outcomes in LGG patients, and that low-risk score patients with grade II tumors showed the best outcomes, while patients with high-risk score and grade III gliomas showed the worst outcomes. In addition to tumor grades II and III, risk score can also be used to stratify IDH wild-type glioma patients. The majority of LGGs belongs to IDH mutation category, while IDH wild-type patients account for only 20-30\% [41]. Moreover, $I D H$ mutation status is a widely acknowledged molecular marker for LGGs, and $I D H$ wild-type patients are characterized by significantly worse survival outcomes than $I D H$ mutant patients $[12,14$, 21]. IDH wild-type LGGs more frequently show molecular genetic alterations similar to GBM, such as TP53 mutation, no $1 \mathrm{p} / 19 \mathrm{q}$ co-deletion, TERT promoter mutation, CDKN2A, EGFR amplification, and PTEN deletion $[12,21,41] .$. In addition, the DNA methylation analysis performed by Cecarelli et al. has revealed subtypes of $I D H$ mutants and IDH wild-type gliomas, and that $I D H$ wild-type subtypes labeled Pilocytic Astrocytoma-like is associated with favorable survival [16]. In this study, a significant difference in OS between the highand low-risk groups was observed among the $I D H$ wild-type patients, and that $I D H$ wild-type patients with high-risk score showed the worst prognosis. These data indicated that threegene signature may act as a prognostic factor for IDH wild-type gliomas.

In summary, we identified and validated a three-gene prognostic signature that can act as a prognostic factor for LGGs using public database. We also found that the expression of all three genes was regulated by promoter methylation. Our findings support the hypothesis that genes that are tightly controlled by promoter methylation level are more likely to be associated with cancer outcomes. Importantly, the three-gene prognostic signature risk performed well in the stratification of grade II and grade III patients and IDH wild-type cohorts, which may help to make the current histology-based tumor classification system more precise and provide better stratification for future clinical trials. In the future, clinical test kits can be developed to detect the expression of three genes in glioma samples, which may help to apply this classification to clinical settings. Regarding the three genes identified in our study, for the first time, high expression of EMILIN3 was shown to predict poor survival in LGGs. Further experiments are needed to explore the precise role of these genes in glioma progression, and their potential application for glioma prognosis.

\section{Acknowledgements}

This work was supported by the National key R\&D program (No.2017YFC0909302 and No. 2016YFC0905001), National Natural Science Foundation of China (No.81703622, No.81673518 and No.81422052).

\section{Disclosure Statement}

No conflict of interests exists.

\section{References}

1 Louis DN, Perry A, Reifenberger G, von Deimling A, Figarella-Branger D, Cavenee WK, Ohgaki H, Wiestler OD, Kleihues P, Ellison DW: The 2016 World Health Organization Classification of Tumors of the Central Nervous System: a summary. Acta Neuropathol 2016;131:803-820.

-2 Abla AA, Turner JD, Sanai N: FoxM1 is vital in the Wnt/beta-catenin signaling pathogenesis of gliomas. World Neurosurg 2012;77:594-596. 


\section{Cellular Physiology Cell Physiol Biochem 2018;47:428-439 and Biochemistry Published online: May 22, $2018 \quad$\begin{tabular}{l|l} 
DOI: 10.1159/000489954 2018 The Author(s). Published by S. Karger AG, Basel \\
www.karger.com/cpb
\end{tabular}}

Zeng et al.: Three-Gene Signature for Lower-Grade Gliomas

3 Brat DJ, Verhaak RG, Aldape KD, Yung WK, Salama SR, Cooper LA, Rheinbay E, Miller CR, Vitucci M, Morozova O, Robertson AG, Noushmehr H, Laird PW, Cherniack AD, Akbani R, Huse JT, Ciriello G, Poisson LM, Barnholtz-Sloan JS, et al.: Comprehensive, Integrative Genomic Analysis of Diffuse Lower-Grade Gliomas. N Engl J Med 2015;372:2481-2498.

4 Huse JT, Holland EC: Targeting brain cancer: advances in the molecular pathology of malignant glioma and medulloblastoma. Nat Rev Cancer 2010;10:319-331.

5 Ricard D, Idbaih A, Ducray F, Lahutte M, Hoang-Xuan K, Delattre JY: Primary brain tumours in adults. Lancet 2012;379:1984-1996.

-6 Louis DN, Perry A, Burger P, Ellison DW, Reifenberger G, von Deimling A, Aldape K, Brat D, Collins VP, Eberhart C, Figarella-Branger D, Fuller GN, Giangaspero F, Giannini C, Hawkins C, Kleihues P, Korshunov A, Kros JM, Beatriz Lopes M, Ng HK, Ohgaki H, Paulus W, Pietsch T, Rosenblum M, Rushing E, Soylemezoglu F, Wiestler O, Wesseling P: International Society Of Neuropathology--Haarlem consensus guidelines for nervous system tumor classification and grading. Brain Pathol 2014;24:429-435.

7 Brennan CW, Verhaak RG, McKenna A, Campos B, Noushmehr H, Salama SR, Zheng S, Chakravarty D, Sanborn JZ, Berman SH, Beroukhim R, Bernard B, Wu CJ, Genovese G, Shmulevich I, Barnholtz-Sloan J, Zou L, Vegesna R, Shukla SA, Ciriello G, Yung WK, Zhang W, Sougnez C, Mikkelsen T, Aldape K, Bigner DD, Van Meir EG, Prados M, Sloan A, Black KL, Eschbacher J, Finocchiaro G, Friedman W, Andrews DW, Guha A, Iacocca M, O’Neill BP, Foltz G, Myers J, Weisenberger DJ, Penny R, Kucherlapati R, Perou CM, Hayes DN, Gibbs R, Marra M, Mills GB, Lander E, Spellman P, Wilson R, Sander C, Weinstein J, Meyerson M, Gabriel S, Laird PW, Haussler D, Getz G, Chin L: The somatic genomic landscape of glioblastoma. Cell 2013;155:462477.

8 Ellis L, Atadja PW, Johnstone RW: Epigenetics in cancer: targeting chromatin modifications. Mol Cancer Ther 2009;8:1409-1420.

-9 Esteller M, Garcia-Foncillas J, Andion E, Goodman SN, Hidalgo OF, Vanaclocha V, Baylin SB, Herman JG: Inactivation of the DNA-repair gene MGMT and the clinical response of gliomas to alkylating agents. N Engl J Med 2000;343:1350-1354.

10 Hegi ME, Diserens AC, Gorlia T, Hamou MF, de Tribolet N, Weller M, Kros JM, Hainfellner JA, Mason W, Mariani L, Bromberg JE, Hau P, Mirimanoff RO, Cairncross JG, Janzer RC, Stupp R: MGMT gene silencing and benefit from temozolomide in glioblastoma. N Engl J Med 2005;352:997-1003.

11 Merlo A, Herman JG, Mao L, Lee DJ, Gabrielson E, Burger PC, Baylin SB, Sidransky D: 5’ CpG island methylation is associated with transcriptional silencing of the tumour suppressor p16/CDKN2/MTS1 in human cancers. Nat Med 1995;1:686-692.

12 Verhaak RG, Hoadley KA, Purdom E, Wang V, Qi Y, Wilkerson MD, Miller CR, Ding L, Golub T, Mesirov JP, Alexe G, Lawrence M, O’Kelly M, Tamayo P, Weir BA, Gabriel S, Winckler W, Gupta S, Jakkula L, Feiler HS, Hodgson JG, James CD, Sarkaria JN, Brennan C, Kahn A, Spellman PT, Wilson RK, Speed TP, Gray JW, Meyerson M, Getz G, Perou CM, Hayes DN: Integrated genomic analysis identifies clinically relevant subtypes of glioblastoma characterized by abnormalities in PDGFRA, IDH1, EGFR, and NF1. Cancer Cell 2010;17:98-110.

-13 Weller M, Weber RG, Willscher E, Riehmer V, Hentschel B, Kreuz M, Felsberg J, Beyer U, Loffler-Wirth H, Kaulich K, Steinbach JP, Hartmann C, Gramatzki D, Schramm J, Westphal M, Schackert G, Simon M, Martens T, Bostrom J, Hagel C, Sabel M, Krex D, Tonn JC, Wick W, Noell S, Schlegel U, Radlwimmer B, Pietsch T, Loeffler M, von Deimling A, Binder H, Reifenberger G: Molecular classification of diffuse cerebral WHO grade II/III gliomas using genome- and transcriptome-wide profiling improves stratification of prognostically distinct patient groups. Acta Neuropathol 2015;129:679-693.

14 Lu C, Ward PS, Kapoor GS, Rohle D, Turcan S, Abdel-Wahab O, Edwards CR, Khanin R, Figueroa ME, Melnick A, Wellen KE, O’Rourke DM, Berger SL, Chan TA, Levine RL, Mellinghoff IK, Thompson CB: IDH mutation impairs histone demethylation and results in a block to cell differentiation. Nature 2012;483:474-U130.

15 Kessler T, Sahm F, Sadik A, Stichel D, Hertenstein A, Reifenberger G, Zacher A, Sabel M, Tabatabai G, Steinbach J, Sure U, Krex D, Grosu AL, Bewerunge-Hudler M, Jones D, Pfister SM, Weller M, Opitz C, Bendszus M, von Deimling A, Platten M, Wick W: Molecular differences in IDH wildtype glioblastoma according to MGMT promoter methylation. Neuro Oncol 2017;10.1093/neuonc/nox160 


\section{Cellular Physiology Cell Physiol Biochem 2018;47:428-439

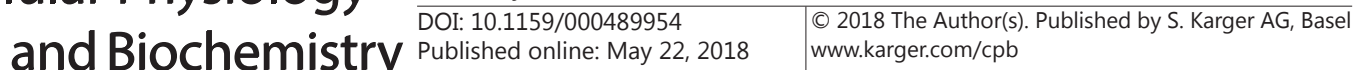

Zeng et al.: Three-Gene Signature for Lower-Grade Gliomas

16 Ceccarelli M, Barthel FP, Malta TM, Sabedot TS, Salama SR, Murray BA, Morozova O, Newton Y, Radenbaugh A, Pagnotta SM, Anjum S, Wang J, Manyam G, Zoppoli P, Ling S, Rao AA, Grifford M, Cherniack AD, Zhang H, Poisson L, Carlotti CG, Jr., Tirapelli DP, Rao A, Mikkelsen T, Lau CC, Yung WK, Rabadan R, Huse J, Brat DJ, Lehman NL, Barnholtz-Sloan JS, Zheng S, Hess K, Rao G, Meyerson M, Beroukhim R, Cooper L, Akbani R, Wrensch M, Haussler D, Aldape KD, Laird PW, Gutmann DH, Noushmehr H, Iavarone A, Verhaak RG: Molecular Profiling Reveals Biologically Discrete Subsets and Pathways of Progression in Diffuse Glioma. Cell 2016;164:550-563.

17 Kawai T, Yamada T, Abe K, Okamura K, Kamura H, Akaishi R, Minakami H, Nakabayashi K, Hata K: Increased epigenetic alterations at the promoters of transcriptional regulators following inadequate maternal gestational weight gain. Sci Rep 2015;5:14224.

-18 Zhu GZ, Yang YL, Zhang YJ, Liu W, Li MP, Zeng WJ, Zhao XL, Chen XP: High Expression of AHSP, EPB42, GYPC and HEMGN Predicts Favorable Prognosis in FLT3-ITD-Negative Acute Myeloid Leukemia. Cell Physiol Biochem 2017;42:1973-1984.

19 Loots CM, Wijnakker R, van Wijk MP, Davidson G, Benninga MA, Omari TI: Esophageal impedance baselines in infants before and after placebo and proton pump inhibitor therapy. Neurogastroenterol Motil 2012;24:758-762, e351-752.

20 Shukla S, Evans JR, Malik R, Feng FY, Dhanasekaran SM, Cao X, Chen G, Beer DG, Jiang H, Chinnaiyan AM: Development of a RNA-Seq Based Prognostic Signature in Lung Adenocarcinoma. J Natl Cancer Inst 2017;109(1): djw200.

21 Mock A, Geisenberger C, Orlik C, Warta R, Schwager C, Jungk C, Dutruel C, Geiselhart L, Weichenhan D, Zucknick M, Nied AK, Friauf S, Exner J, Capper D, Hartmann C, Lahrmann B, Grabe N, Debus J, von Deimling A, Popanda O, Plass C, Unterberg A, Abdollahi A, Schmezer P, Herold-Mende C: LOC283731 promoter hypermethylation prognosticates survival after radiochemotherapy in IDH1 wild-type glioblastoma patients. Int J Cancer 2016;139:424-432.

-22 Suzuki H, Aoki K, Chiba K, Sato Y, Shiozawa Y, Shiraishi Y, Shimamura T, Niida A, Motomura K, Ohka F, Yamamoto T, Tanahashi K, Ranjit M, Wakabayashi T, Yoshizato T, Kataoka K, Yoshida K, Nagata Y, SatoOtsubo A, Tanaka H, Sanada M, Kondo Y, Nakamura H, Mizoguchi M, Abe T, Muragaki Y, Watanabe R, Ito I, Miyano S, Natsume A, Ogawa S: Mutational landscape and clonal architecture in grade II and III gliomas. Nat Genet 2015;47:458-468.

23 Zhang CM, Brat DJ: Genomic profiling of lower-grade gliomas uncovers cohesive disease groups: implications for diagnosis and treatment. Chin J Cancer 2016;35:12.

24 Noushmehr H, Weisenberger DJ, Diefes K, Phillips HS, Pujara K, Berman BP, Pan F, Pelloski CE, Sulman EP, Bhat KP, Verhaak RG, Hoadley KA, Hayes DN, Perou CM, Schmidt HK, Ding L, Wilson RK, Van Den Berg D, Shen H, Bengtsson H, Neuvial P, Cope LM, Buckley J, Herman JG, Baylin SB, Laird PW, Aldape K: Identification of a $\mathrm{CpG}$ island methylator phenotype that defines a distinct subgroup of glioma. Cancer Cell 2010;17:510-522.

-25 Reifenberger G, Wirsching HG, Knobbe-Thomsen CB, Weller M: Advances in the molecular genetics of gliomas - implications for classification and therapy. Nat Rev Clin Oncol 2017;14:434-452.

-26 Zhang Z, Tang H, Wang Z, Zhang B, Liu W, Lu H, Xiao L, Liu X, Wang R, Li X, Wu M, Li G: MiR-185 targets the DNA methyltransferases 1 and regulates global DNA methylation in human glioma. Mol Cancer 2011;10:124.

27 Fumoto S, Tanimoto K, Hiyama E, Noguchi T, Nishiyama M, Hiyama K: EMP3 as a candidate tumor suppressor gene for solid tumors. Expert Opin Ther Targets 2009;13:811-822.

-28 Alaminos M, Davalos V, Ropero S, Setien F, Paz MF, Herranz M, Fraga MF, Mora J, Cheung NK, Gerald WL, Esteller M: EMP3, a myelin-related gene located in the critical 19q13.3 region, is epigenetically silenced and exhibits features of a candidate tumor suppressor in glioma and neuroblastoma. Cancer Res 2005;65:2565-2571.

29 Mellai M, Piazzi A, Caldera V, Annovazzi L, Monzeglio O, Senetta R, Cassoni P, Schiffer D: Promoter hypermethylation of the EMP3 gene in a series of 229 human gliomas. Biomed Res Int 2013;2013:756302.

-30 Pasini A, Iorio P, Bianchi E, Cerasoli S, Cremonini AM, Faedi M, Guarnieri C, Guiducci G, Riccioni L, Molinari C, Rengucci C, Calistri D, Giordano E: LOH 19q indicates shorter disease progression-free interval in lowgrade oligodendrogliomas with EMP3 methylation. Oncol Rep 2012;28:2271-2277.

31 Gao YF, Zhu T, Mao CX, Liu ZX, Wang ZB, Mao XY, Li L, Yin JY, Zhou HH, Liu ZQ: PPIC, EMP3 and CHI3L1 Are Novel Prognostic Markers for High Grade Glioma. Int J Mol Sci 2016;17:1808. 


\section{Cellular Physiology Cell Physiol Biochem 2018:47:428-439

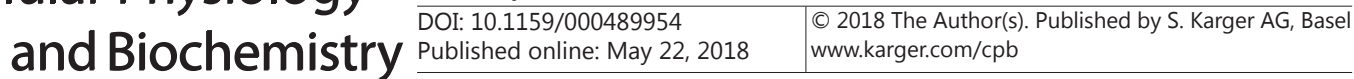 \\ Zeng et al.: Three-Gene Signature for Lower-Grade Gliomas}

-32 Jun F, Hong J, Liu Q, Guo Y, Liao Y, Huang J, Wen S, Shen L: Epithelial membrane protein 3 regulates TGFbeta signaling activation in CD44-high glioblastoma. Oncotarget 2017;8:14343-14358.

-33 Gao F, Huang HJ, Gao J, Li ZS, Ma SR: GSH2 promoter methylation in pancreatic cancer analyzed by quantitative methylation-specific polymerase chain reaction. Oncol Lett 2015;10:387-391.

34 Cools J, Mentens N, Odero MD, Peeters P, Wlodarska I, Delforge M, Hagemeijer A, Marynen P: Evidence for position effects as a variant ETV6-mediated leukemogenic mechanism in myeloid leukemias with a $t(4 ; 12)$ (q11-q12;p13) or t(5;12)(q31;p13). Blood 2002;99:1776-1784.

-35 Soler G, Kaltenbach S, Dobbelstein S, Broccardo C, Radford I, Mozziconacci MJ, Bernard OA, PenardLacronique V, Delabesse E, Romana SP: Identification of GSX2 and AF10 as NUP98 partner genes in myeloid malignancies. Blood Cancer J 2013;3:e124.

-36 Di Giacomo D, La Starza R, Barba G, Pierini V, Baldazzi C, Storlazzi CT, Daniele G, Forghieri F, Borlenghi E, Testoni N, Mecucci C: 4q12 translocations with GSX2 expression identify a CD7(+) acute myeloid leukaemia subset. Br J Haematol 2015;171:141-145.

-37 Hassan NZA, Mokhtar NM, Sin TK, Rose IM, Sagap I, Harun R, Jamal R: Integrated Analysis of Copy Number Variation and Genome-Wide Expression Profiling in Colorectal Cancer Tissues. Plos One 2014;9(4):e92553.

38 Xiong A, Kundu S, Forsberg-Nilsson K: Heparan sulfate in the regulation of neural differentiation and glioma development. Febs j 2014;281:4993-5008.

39 Wade A, Robinson AE, Engler JR, Petritsch C, James CD, Phillips JJ: Proteoglycans and their roles in brain cancer. Febs j 2013;280:2399-2417.

40 Phillips JJ, Huillard E, Robinson AE, Ward A, Lum DH, Polley MY, Rosen SD, Rowitch DH, Werb Z: Heparan sulfate sulfatase SULF2 regulates PDGFRalpha signaling and growth in human and mouse malignant glioma. J Clin Invest 2012;122:911-922.

41 Appin CL, Brat DJ: Biomarker-driven diagnosis of diffuse gliomas. Mol Aspects Med 2015;45:87-96. 